\section{Human anti-mouse antibodies}

S. Holdenrieder ${ }^{1}$ und P. Stieber ${ }^{2}$

${ }^{1}$ Institut für Laboratoriumsmedizin, Deutsches Herzzentrum München, Klinik an der Technischen Universität München, München, Deutschland

${ }^{2}$ Institut für Laboratoriumsmedizin, Klinikum der Universität München (LMU), München, Deutschland

\section{Synonym(e) HAMA}

Englischer Begriff human anti-mouse antibodies

Definition Heterophile Antikörper, die nach einer Applikation von Maus-Immunglobulinen im Zuge von diagnostischen oder therapeutischen Maßnahmen gebildet werden.

Struktur $>$ Immunglobuline

Funktion - Pathophysiologie Im Rahmen einer Immunszintigrafie oder einer Immuntherapie mit Maus-Immunglobulinen werden heterophile Anti-Maus-Antikörper gebildet, die in Testsystemen, in denen monoklonale Maus-Antikörper verwendet werden, zu falsch positiven Ergebnissen führen können. Diese heterophilen Antikörper können auch bei Patienten, die mit „Frischzellen" behandelt worden sind, vorkommen und falsch hohe Tumormarkerwerte vortäuschen. Heterophile
Antikörper werden nach intensivem Kontakt mit Tieren jedoch sehr selten auch bei Normalpersonen gefunden.

\section{Untersuchungsmaterial - Entnahmebedingungen Serum.}

Referenzbereich - Erwachsene $<40 \mu \mathrm{g} / \mathrm{L}$ (methodenabhängig).

Indikation Abklärung plötzlich erhöhter oder unerklärlich hoher Tumormarkerwerte ohne klinisches Korrelat.

Interpretation Heterophile Anti-Maus-Antikörper sollten bei plötzlich erhöhten oder unerklärlich hohen Tumormarkerwerten ohne klinisches Korrelat untersucht werden. Erhöhte HAMAWerte erübrigen eine weitere Diagnostik mit Tumormarkern.

Diagnostische Wertigkeit Abklärung plötzlich erhöhter oder unerklärlich hoher Tumormarkerwerte ohne klinisches Korrelat.

\section{Literatur}

Diamandis E, Fritsche HA, Lilja H (2002) Tumor markers. Physiology, pathobiology, technology, and clinical applications. AACC Press, Washington, DC

Stieber P, Heinemann V (2008) Sinnvoller Einsatz von Tumormarkern. J Lab Med 32:339-360 